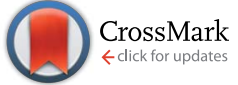

Cite this: J. Mater. Chem. A, 2015, 3 , 4909

Received 24th November 2014 Accepted 19th January 2015

DOI: $10.1039 / c 4 t a 06416 j$

www.rsc.org/MaterialsA

\section{Fast and low temperature growth of electron transport layers for efficient perovskite solar cells $\uparrow$}

\author{
Jie Zhang, ${ }^{a}$ Emilio José Juárez-Pérez, ${ }^{\mathrm{b}}$ Iván Mora-Seró, ${ }^{\mathrm{b}}$ Bruno Viana ${ }^{\mathrm{a}}$ \\ and Thierry Pauporté a $^{*}$
}

We describe a fast, simple and low temperature electrochemical technique for the preparation of zinc oxide layers on rigid and flexible substrates. The layers, prepared from a zinc nitrate precursor, are of high structural and optical quality. They have been optimized to be applied as efficient electron transport layers in $\mathrm{CH}_{3} \mathrm{NH}_{3} \mathrm{Pbl}_{3}$-sensitized perovskite solar cells (PSCs). We show that an electrodeposition time of only two minutes and a low processing temperature are sufficient to fabricate solar cells with a power conversion efficiency close to $11 \%$, with a high short circuit current and a small $J-V$ curve hysteresis. The key parameters of the cell functioning have been analyzed over a large applied voltage range by the impedance spectroscopy technique. The solar cell characteristic changes with the $\mathrm{ZnO}$ layer deposition time are explained by the variation of the recombination and charge transfer resistances.

\section{Introduction}

Solution-processed organic and hybrid organic-inorganic solar cells have been intensely developed during the last two decades. ${ }^{1-3}$ Very recently, perovskite solar cells (PSCs) have emerged as the most promising new generation of hybrid photovoltaic devices. ${ }^{\mathbf{4}-13}$ The power conversion efficiency of this newcomer has increased fast and very recently a certified power conversion efficiency (PCE) higher than 20\% has been reported. ${ }^{14}$ The most extended perovskite materials used for the solar light absorption and charge generation are hybrid organicinorganic compounds with a $3 \mathrm{D}$ crystal structure of general formula $\mathrm{CH}_{3} \mathrm{NH}_{3} \mathrm{PbX}_{3}$ (with $\mathrm{X}=\mathrm{Cl}, \mathrm{Br}$ or I). The electron and hole charge collection is ensured by the two adjacent selective contact phases that generate the driving force for the charge separation. The electrons are usually selectively collected by a wide bandgap oxide material, also called the electron transport layer (ETL), while holes are selectively transferred to a hole transport layer (HTL), usually made of an organic molecular glass. Spiro-OMeTAD is the most common material employed for this purpose.

\footnotetext{
${ }^{a}$ Institut de Recherche de Chimie-Paris (IRCP), CNRS-Chimie ParisTech-Paris Sciences et Lettres UMR8247, 11 rue Pierre et Marie Curie, 75005 Paris, France. E-mail: thierry. pauporte@chimie-paristech.fr

${ }^{b}$ University Jaume I, Department of Physics, Photovoltaic and Optoelectronic Devices Group, Castellon de La Plana 12071, Spain

$\uparrow$ Electronic supplementary information (ESI) available: SEM view of i-ZnO deposit at short deposition time, Raman and photoluminescence spectra of the $\mathrm{i}-\mathrm{ZnO}$ layers, bandgap determination and photoluminescence of the $\mathrm{CH}_{3} \mathrm{NH}_{3} \mathrm{PbI}_{3}$ layer, IPCE curves, $R_{\mathrm{S}}$ and capacitance cell parameters at various voltages and flexible cell characteristics. See DOI: $10.1039 / \mathrm{c} 4 \mathrm{ta} 06416 \mathrm{j}$
}

Currently, most state-of-the-art PSCs utilize mesoporous $\mathrm{TiO}_{2}$ scaffold layers on top of a compact titania layer to provide a substrate on which the perovskite can be grown. ${ }^{7}$ The preparation of these layers requires annealing and sintering processes at high temperature, typically $500{ }^{\circ} \mathrm{C}$. On the other hand, other wide bandgap oxides and low temperature processing of the ETL are much less-documented. The low temperature and fast processing are desirable to reduce the production cost and for the preparation of flexible lightweight devices on plastic substrates. $\mathrm{ZnO}$ is a wide bandgap semiconductor with an electron affinity similar to $\mathrm{TiO}_{2}$. It can be grown by various techniques with a high structural quality at low temperature. ${ }^{15,16}$ It is therefore a very promising candidate for the PSC application. ${ }^{17-24}$ Moreover, the conductivity of $\mathrm{ZnO}$ is several orders of magnitude higher than the $\mathrm{TiO}_{2}$ one and that favors the electron transport toward the front contact. ${ }^{25,26}$ Kelly et al. ${ }^{21}$ have recently reported remarkably high efficiency PSCs using a thin layer of dense planar ZnO prepared by spin-coating. The review of the literature on $\mathrm{ZnO}$-PSCs also indicates that remarkably high $J_{\text {sc }}$ can be achieved with ZnO ETM. ${ }^{17,20}$

The present work focuses on the preparation by electrochemical deposition of $\mathrm{ZnO}$ layers with tailored properties. The advantages of the technique include the deposition of high quality materials at low temperature, the precise control of the (nano)structure morphology and thickness, the control of the electrical properties and the excellent electrical contact between the deposited layers and the substrate. ${ }^{27-29}$ Hereafter, we describe the fast and low temperature electrochemical growth of fully covered $\mathrm{ZnO}$ layers using zinc nitrate as the deposition precursor. We show that the deposited material is $\mathrm{ZnO}$ and is of high optical and structural quality. The interest of using this layer as an ETL is demonstrated. After sensitization by 
$\mathrm{CH}_{3} \mathrm{NH}_{3} \mathrm{PbI}_{3}$ and cell completion, we have found that the optimized ETL deposition time is very short, only 2 minutes. These characteristics make this method extremely interesting since the $\mathrm{TiO}_{2}$ alternative for ETL requires much more time and temperature for an optimized efficiency., ${ }^{\mathbf{4 , 5}}$ PSCs based on this electrodeposited ZnO layer achieved a PCE of $10.6 \%$ with a low $J-V$ curve hysteresis.

\section{Experimental}

\subsection{ZnO layer electrodeposition}

The ZnO films were prepared directly on ITO coated glass substrates. The substrates were carefully cleaned with soap, rinsed with deionized water prior to sonication for $5 \mathrm{~min}$ in ethanol and $5 \mathrm{~min}$ in acetone. The electrochemical deposition was carried out in a three-electrode cell. The counter-electrode was a zinc wire and the reference electrode was a saturated calomel electrode (SCE) (with a potential at $+0.25 \mathrm{~V} v s$. NHE) placed in a separate compartment maintained at room temperature. To ensure a deposition as homogeneous as possible, the substrate was fixed and connected to a rotating electrode and the deposition was performed at a constant rotation speed of 145 rotations per minute (rpm). The deposition bath was a solution of $\mathrm{Zn}\left(\mathrm{NO}_{3}\right)_{2}$ at a concentration of 0.08 $\mathrm{M}$ dissolved in MilliQ quality water $(18.2 \mathrm{M} \Omega \mathrm{cm})$ maintained at $60{ }^{\circ} \mathrm{C} .^{30,31}$ The deposition was performed at a constant applied voltage of $-1.15 \mathrm{~V}$ per SCE for various times. The cathodic reaction mechanism for $\mathrm{ZnO}$ deposition is: $\mathbf{2 8}^{\mathbf{2 8}}$

$$
\begin{gathered}
\mathrm{NO}_{3}{ }^{-}+\mathrm{H}_{2} \mathrm{O}+2 \mathrm{e}^{-} \rightarrow \mathrm{NO}_{2}^{-}+2 \mathrm{OH}^{-} \\
\mathrm{Zn}^{2+}+2 \mathrm{OH}^{-} \rightarrow \mathrm{ZnO}+\mathrm{H}_{2} \mathrm{O}
\end{gathered}
$$

\subsection{Solar cell preparation and characterization}

The $\mathrm{ZnO}$ layers were dried at $150{ }^{\circ} \mathrm{C}$ for $1 \mathrm{~h}$. The organic-inorganic perovskite $\mathrm{CH}_{3} \mathrm{NH}_{3} \mathrm{PbI}_{3}$ was deposited by a sequential method inspired from the literature. ${ }^{6} 70 \mu \mathrm{L}$ of $\mathrm{PbI}_{2}$ solution at $70{ }^{\circ} \mathrm{C}$ (dissolved in $\mathrm{N}, \mathrm{N}$-dimethylformamide at a concentration of $460 \mathrm{mg} \mathrm{mL}^{-1}$ ) was spin-coated on top of the $\mathrm{ZnO}$ layer at 3000 $\mathrm{rpm}$. for $15 \mathrm{~s}$. This step was repeated once. After drying at $70{ }^{\circ} \mathrm{C}$ for 30 minutes in air, the substrate was dipped into a solution of $\mathrm{CH}_{3} \mathrm{NH}_{3} \mathrm{I}$ in 2-propanol $\left(10 \mathrm{mg} \mathrm{mL} \mathrm{mL}^{-1}\right.$ ) for $30 \mathrm{~s}$ (optimized duration), then dried at $70{ }^{\circ} \mathrm{C}$ for $30 \mathrm{~min}$. $\mathrm{CH}_{3} \mathrm{NH}_{3} \mathrm{I}$ was prepared according to ref. 32. Subsequently, the spiro-OMeTADbased hole-transport layer was deposited using a solution containing $80 \mathrm{mg}$ spiro-OMeTAD, $28.5 \mu \mathrm{L}$ 4-tertbutylpyridine and $17.5 \mu \mathrm{L}$ of lithium-bis(trifluoromethanesulfonyl)imide (Li-TFSI) (520 $\mathrm{mg}$ Li-TFSI in $1 \mathrm{~mL}$ acetonitrile) all dissolved in $1 \mathrm{ml}$ chlorobenzene. This precursor solution was deposited by spin coating at $2000 \mathrm{rpm}$ for $15 \mathrm{~s}$. Finally, a $100 \mathrm{~nm}$-thick silver layer was deposited by thermal evaporation on the spiro-OMeTAD layer as a back contact.

The $J-V$ curves were recorded using a Keithley 2400 digital sourcemeter, with a $0.15 \mathrm{~V} \mathrm{~s}^{-1}$ voltage sweep rate, for which the measured curve hysteresis was low. The solar cells were illuminated with a solar simulator (Abet Technology Sun 2000) filtered to mimic AM 1.5G conditions. The illuminated surface was delimited by a black mask with an aperture diameter of 3 $\mathrm{mm}$. The power density was calibrated to $100 \mathrm{~mW} \mathrm{~cm}^{-2}$ by using a reference silicon solar cell. The reproducibility of the performances was checked on several cells prepared from different batches. The impedance spectra were recorded under 0.95-1 sun illumination provided by a Schott lamp, between 600 $\mathrm{kHz}$ and $0.12 \mathrm{~Hz}$, using a Solartron FRA1255 frequency response analyzer coupled with a PAR273 EGG potentiostat. The AC signal was $20 \mathrm{mV}$.

The film thicknesses were measured with a Dektak 6M stylus profilometer. The sample morphologies were examined with a high resolution Ultra 55 Zeiss FEG scanning electron microscope (FE-SEM) at an acceleration voltage of $10 \mathrm{kV}$. The film structure was characterized using a Phillips X-Pert high-resolution X-ray diffractometer (XRD) operating at $40 \mathrm{kV}$ and $45 \mathrm{~mA}$ and using CuK $\alpha$ radiation with $\lambda=1.54056 \AA$. The total transmission and total reflection of the film were measured with a Cary 5000 UV-Vis-NIR spectrophotometer equipped with an integrating sphere. The absorbance spectra were calculated from these two parameters. The photoluminescence measurement system combined a YAG:Nd laser and a HR250 monochromator (Jobin-Yvon) coupled to a UV-enhanced intensified charge-coupled device (ICCD; Roper). The excitation wavelength was $266 \mathrm{~nm}$ for $\mathrm{ZnO}$ and $600 \mathrm{~nm}$ for perovskite characterizations. Raman scattering measurements were performed at room temperature with a Renishaw INVIA apparatus equipped with a microscope and a CCD detector. A $532 \mathrm{~nm}$ solid-state green laser was used for off-resonance excitation with $50 \mathrm{~mW}$ power. The instrument was calibrated using a silicon standard.

\section{Results and discussion}

The oxide layers for electron transport were grown on a ITO/ glass substrate by electrodeposition using $0.08 \mathrm{M} \mathrm{Zn}\left(\mathrm{NO}_{3}\right)_{2}$ as the zinc and hydroxide precursor with an applied potential of $-1.15 \mathrm{~V} v s$. SCE (saturated calomel electrode) and a temperature of $60{ }^{\circ} \mathrm{C}$. The technique generated n-type doped $\mathrm{ZnO}$ layer that

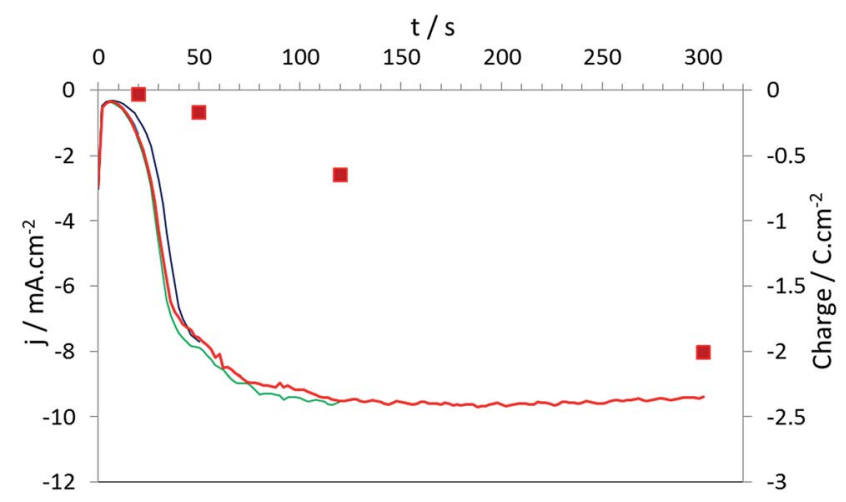

Fig. 1 Variation of the current density (lines) and electrical charge exchanged (red dots) with deposition time $\left(E=-1.15 \mathrm{~V}\right.$ per SCE, $T^{\circ}=$ $\left.60{ }^{\circ} \mathrm{C}\right)$. Three deposition curves for different deposition times are presented in blue (50 s), green (120 s) and red (300 s). 
is hereafter noted as i-ZnO. Fig. 1 shows the variation of the deposition current due to the nitrate reduction reaction on the ITO electrode surface. The cathodic current rapidly decreased before stabilization at a low value of $-0.35 \mathrm{~mA} \mathrm{~cm}^{-2}$ and then leveled off after $20 \mathrm{~s}$ of deposition time $\left(t_{\mathrm{d}}\right)$. After $100 \mathrm{~s}$, the deposition current reached a plateau at $-9.5 \mathrm{~mA} \mathrm{~cm}{ }^{-2}$. The shape of the curve is similar to that observed for the electrodeposition of $\mathrm{ZnO}$ at room temperature using a chloride medium. ${ }^{33}$ It is explained by the progressive nucleation of $\mathrm{ZnO}$ on the ITO surface. We show below that more than $100 \mathrm{~s}$ is necessary to fully cover the electrode surface. The electrical charge exchanged during the deposition of the investigated layers (corresponding to $20 \mathrm{~s}, 50 \mathrm{~s}, 120 \mathrm{~s}$ and $300 \mathrm{~s}$ of $t_{\mathrm{d}}$ ) is plotted in Fig. 1. From this parameter, we have calculated the equivalent $\mathrm{ZnO}$ layer thickness deposited onto the electrode for various electrodeposition times. The values are gathered in Table 1 and are compared to the actual layer thicknesses measured by profilometry. The latter values are significantly higher than the calculated ones with a gap between the two values which decreases with time. We also observed that the roughness increased with the $t_{\mathrm{d}}$ (Table 1$)$.

Scanning electron microscopy (SEM) images of the layers are shown in Fig. 2a-d. After $20 \mathrm{~s}$, the deposit is made of grains dispersed on the ITO surface (Fig. S1, ESI $\dagger$ ). After $50 \mathrm{~s}$ the substrate is not fully covered and in Fig. 2a the arrows point out the bare ITO substrate zones uncovered by the deposit. However, after $120 \mathrm{~s}$, a layer made of large grains that perfectly covers the ITO substrate is observed (Fig. 2b-c). From the crosssectional view of Fig. $2 \mathrm{~d}$, it is observed that some prominent $\mathrm{ZnO}$ grains emerge from the layers that explain the roughness observed by profilometry. A close inspection of the grain surface shows no crystal facets but ten-nanometer-sized asperities (Fig. 2c). Moreover the cross-sectional view (Fig. 2d) exhibits the presence of pinholes in the grains. These voids suggest some porosity of the layers that explains in part the underestimation of the calculated layer thicknesses compared to the measured ones in Table 1.

The i-ZnO layers have been characterized after an annealing treatment in air at $150{ }^{\circ} \mathrm{C}$ for $1 \mathrm{~h}$. The XRD measurements are presented in Fig. 3a. For $20 \mathrm{~s}$ of $t_{\mathrm{d}}$ no ZnO was detected. After 50 $\mathrm{s}$, the (101) $\mathrm{ZnO}$ reflection peaks could be observed and for

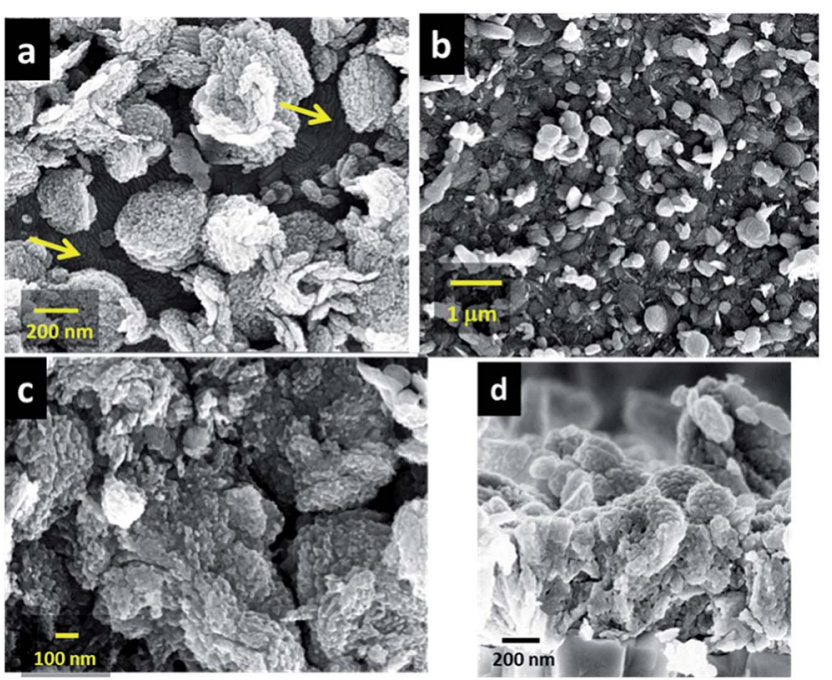

Fig. 2 FE-SEM images of (a) i-ZnO layer deposited on ITO for $50 \mathrm{~s}$, (bd) i-ZnO layer deposited on ITO for $120 \mathrm{~s}$ (b and c) top views, (d) crosssectional view.

longer deposition times the main diffraction peaks were assigned to the hexagonal wurtzite structure of $\mathrm{ZnO}$. The comparison of the relative intensity of the peaks with the JCPDS 036-145134 reference card $^{34}$ shows that there was no special texturation of the layer. Raman spectra of the layer are presented in Fig. S2a (ESI $\dagger$ ). The optical phonons at the $G$ point of the Brillouin zone belong to the representation: $\Gamma_{\text {opt }}=\mathrm{A}_{1}(z)+$ $2 \mathrm{~B}_{1}+\mathrm{E}_{1}(x, y)+2 \mathrm{E}_{2}$ where $x, y$, and $z$ represent the polarization directions. $\mathrm{A}_{1}$ and $\mathrm{E}_{1}$ modes are polar and split into TO-transverse optical and LO-longitudinal optical components. ${ }^{35}$ The $\mathrm{E}_{2}$ modes are Raman active only. The $\mathrm{B}_{1}$ modes are infrared and Raman inactive or silent modes. The dominant emission peaks at $100 \mathrm{~cm}^{-1}$ and $438 \mathrm{~cm}^{-1}$ are attributed to the low- $\mathrm{E}_{2}$ and high$\mathrm{E}_{2}$ modes of non-polar optical phonons, respectively. The broad peak at about $331 \mathrm{~cm}^{-1}$, seen in the spectrum of $\mathrm{i}-\mathrm{ZnO}(300 \mathrm{~s})$ is attributed to a $\mathrm{E}_{2}^{\mathrm{H}}-\mathrm{E}_{2}^{\mathrm{L}}$ (multiphonon) mode. ${ }^{36,37}$ The sharpness and high intensity of the $\mathrm{E}_{2}$-mode emissions confirm the wellcrystallization of the wurtzite $\mathrm{ZnO}$ films beyond two minutes of deposition time.

Table 1 Effect of $\mathrm{i}-\mathrm{ZnO}$ deposition time on the layer characteristics after annealing at $150{ }^{\circ} \mathrm{C}$ for $1 \mathrm{~h}$

\begin{tabular}{|c|c|c|c|c|c|c|}
\hline $\begin{array}{l}\text { Deposition } \\
\text { time/s }\end{array}$ & $Q^{a} / \mathrm{C} \mathrm{cm}{ }^{-2}$ & Calculated thickness ${ }^{b} / \mathrm{nm}$ & Measured thickness/nm & $R_{\mathrm{q}}{ }^{c} / \mathrm{nm}$ & $\lambda_{\mathrm{UV}}{ }^{d} / \mathrm{eV}(\mathrm{nm})$ & $E_{\mathrm{g}}{ }^{e} / \mathrm{eV}$ \\
\hline 20 & 0.031 & 23 & $\mathrm{x}$ & $\mathrm{X}$ & $\mathrm{X}$ & $\mathrm{X}$ \\
\hline 120 & 0.645 & 485 & 780 & 65 & $3.23(384)$ & 3.38 \\
\hline 300 & 2.005 & 1510 & 1900 & 120 & $3.22(385)$ & 3.32 \\
\hline
\end{tabular}

${ }^{a} Q$, the electrical charge density exchanged during the electrodeposition process. ${ }^{b}$ Obtained from the measured total electrical charge exchanged, see Fig. 1, as: $D(\mu \mathrm{m})=\frac{Q}{n F} \frac{\mathrm{MW}}{\rho}=0.7519 Q\left(\mathrm{C} \mathrm{cm}^{-2}\right)$, with $n$ being the number of electrons exchanged in the electrochemical reaction (1) and (2) $(n=2), F$, the Faraday constant (96 $\left.485 \mathrm{C} \mathrm{mol}^{-1}\right)$, MW, the molar weight of $\mathrm{ZnO}\left(81.4 \mathrm{~g} \mathrm{~mol}^{-1}\right)$ and $\rho$, the density of $\mathrm{ZnO}\left(5.61 \mathrm{~g} \mathrm{~cm}{ }^{-3}\right) .{ }^{c} \mathrm{Root}$ mean square of roughness (RMS). ${ }^{d}$ Near-band edge UV photoemission energy (wavelength). ${ }^{e}$ Optical bandgap measured from the transmittance and reflectance spectra. 

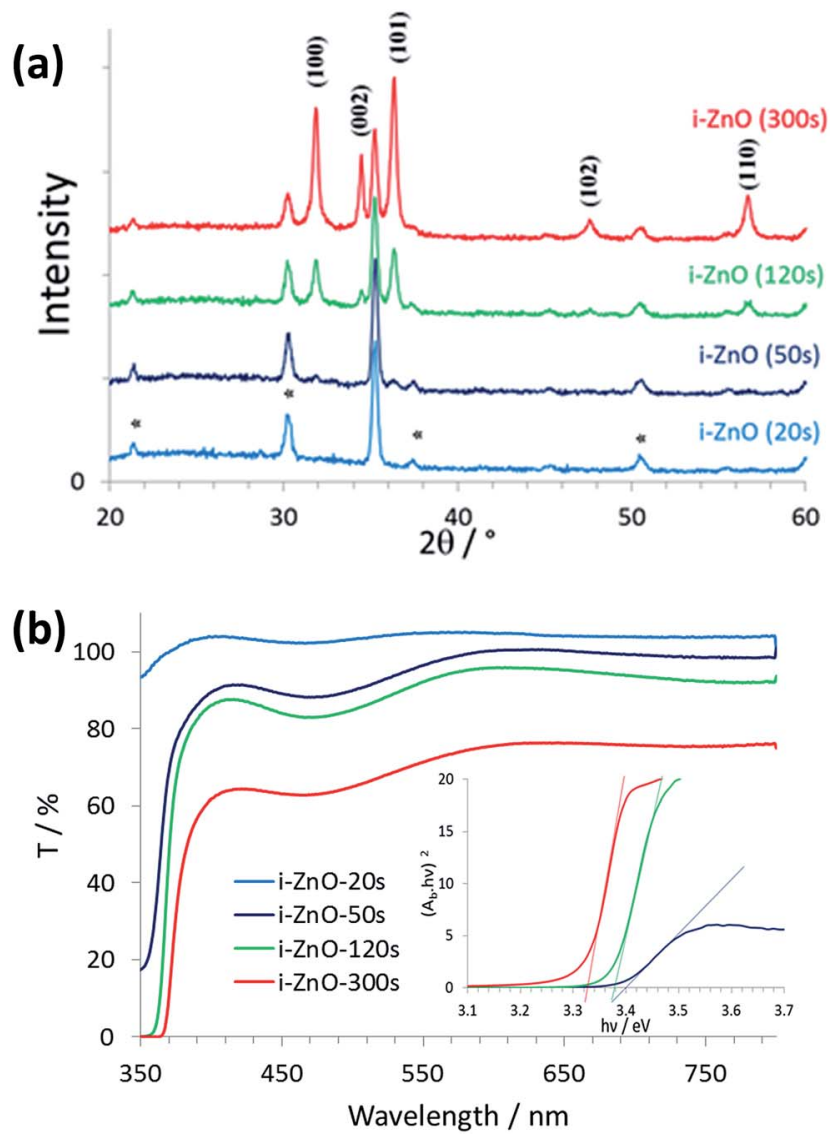

Fig. 3 (a) XRD patterns of $\mathrm{i}-\mathrm{ZnO}$ layers (the ITO substrate reflections are marked with stars). (b) Total optical transmittance of the i-ZnO layer for various deposition times. The inset shows the direct optical bandgap determination.

The optical properties of the layer are presented in Fig. $3 \mathrm{~b}$. The i-ZnO(20 s) transmission curve exhibits a very small UV-edge due to its thinness and noncovering nature. For i-ZnO(50 s) the low wavelength transmission is not zero because the $\mathrm{ZnO}$ electrodeposited layer does not fully cover the ITO substrate. From the absorption edge at about $370 \mathrm{~nm}$, the $\mathrm{ZnO}$ optical bandgap $\left(E_{g}\right)$ has been calculated for the various layers (see inset in Fig. $3 \mathrm{~b}$ ) and the values are gathered in Table 1 . They slightly decreased with the deposition time. The photoluminescence at room temperature is shown in Fig. S2b (ESI $\dagger$ ). The spectra are characterized by a strong near-band-edge UV emission which increases in intensity with the deposition time and then with the layer thickness. There is also a weak green emission centered at $530 \mathrm{~nm}$ due to intrinsic defects. The intensity ratio between the UV emission and the visible one clearly increases with $t_{\mathrm{d}}$. It is the signature of an improvement of the layer structural quality with this parameter. The wavelengths of the UV emission, reported in Table 1, slightly shift towards a lower energy with the oxide deposition time, which maybe because of a reduction of the hydroxide content in the deposit.

The i-ZnO layers have been sensitized by the $\mathrm{CH}_{3} \mathrm{NH}_{3} \mathrm{PbI}_{3}$ hybrid perovskite using a two-step technique described in the Experimental section. ${ }^{\mathbf{6} 17}$ The perovskite deposition process
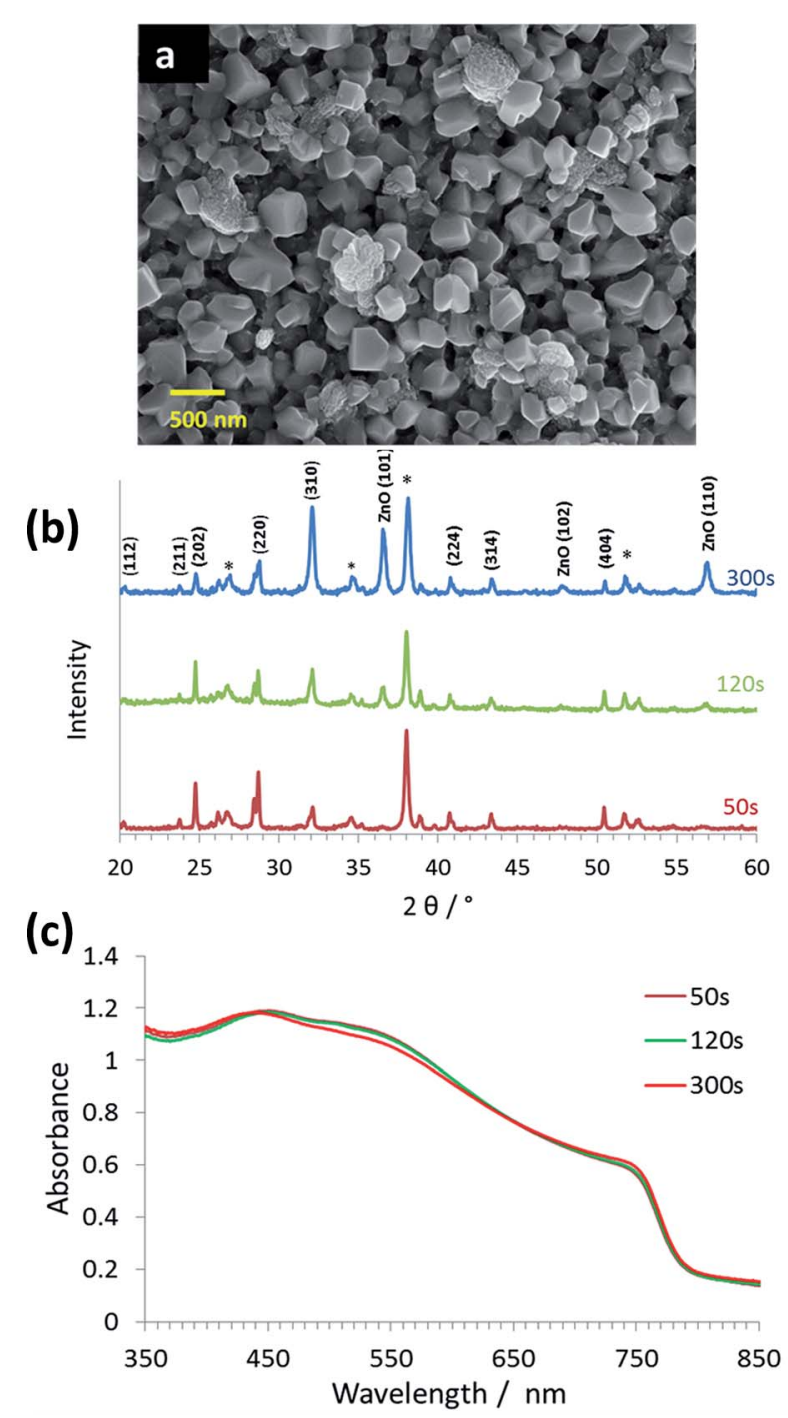

Fig. 4 (a) FE-SEM top view of a $\mathrm{i}-\mathrm{ZnO}(120 \mathrm{~s})$ layer sensitized with $\mathrm{CH}_{3} \mathrm{NH}_{3} \mathrm{Pbl}_{3}$. (b) XRD patterns (the substrate reflections are marked with stars) and (c) absorbance of $\mathrm{i}-\mathrm{ZnO} / \mathrm{CH}_{3} \mathrm{NH}_{3} \mathrm{Pbl}$ layers.

resulted in the covering of the $\mathrm{i}-\mathrm{ZnO}$ surface by grains with a mean size of about $300 \mathrm{~nm}$ (Fig. 4a). The XRD patterns, shown in Fig. $4 \mathrm{~b}$, are characteristics of well-crystallized $\mathrm{CH}_{3} \mathrm{NH}_{3} \mathrm{PbI}_{3}$ irrespective of the $\mathrm{i}-\mathrm{ZnO}$ deposition time used. The mean reflection peaks are indexed in Fig. $4 \mathrm{~b}$. The absorbance spectra are shown in Fig. 4c. The lead iodide perovskite layers deposited on ZnO scaffolds show a panchromatic absorption of light with spectra that extend from the near-UV to near infra-red regions. The absorbance intensity does not depend on the i-ZnO deposition time and also on the roughness of the initial $\mathrm{i}-\mathrm{ZnO}$ layer. The band edge analysis shows that the prepared $\mathrm{CH}_{3} \mathrm{NH}_{3} \mathrm{PbI}_{3}$ has a direct bandgap of $1.58 \mathrm{eV}$ (Fig. S3a, ESI $\dagger$ ). The high structural quality of the perovskite layers has been confirmed by the photoluminescence measurements at room temperature with a strong emission peak centered at $777 \mathrm{~nm}$ (Fig. S3b, ESI $\dagger$ ).

The sensitized i-ZnO structures were completed by spincoating a thin HTL of spiro-OMeTAD. Finally, a silver contact was evaporated on the top of the HTL. Fig. 5a shows a SEM 

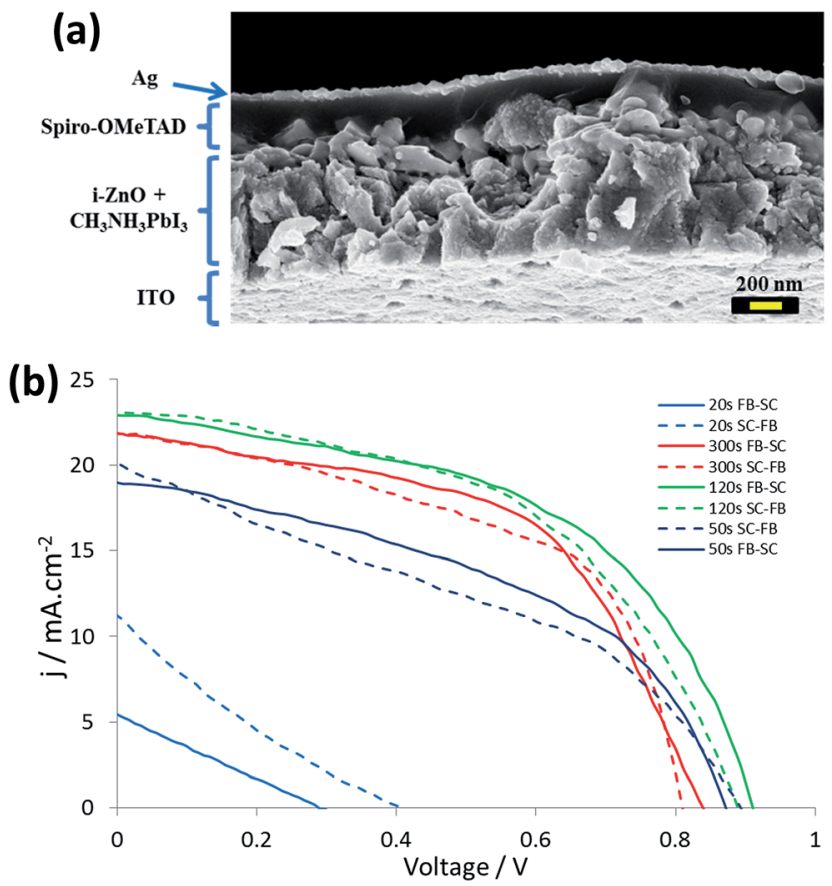

Fig. 5 (a) FE-SEM cross-sectional view of ITO/i- $\mathrm{ZnO} / \mathrm{CH}_{3} \mathrm{NH}_{3} \mathrm{Pbl}_{3} / \mathrm{Ag}$ cell. (b) Effect of $\mathrm{i}-\mathrm{ZnO}$ deposition time on the $J-V$ curves. $(100 \mathrm{~mW}$ $\mathrm{cm}^{-2}$ AM1.5G filtered illumination). Full line FB-SC, dashed line SC-FB scanning directions. Pale blue: $\mathrm{i}-\mathrm{ZnO}(20 \mathrm{~s})$; blue: $\mathrm{i}-\mathrm{ZnO}(50 \mathrm{~s})$; green: i$\mathrm{ZnO}(120 \mathrm{~s})$; red: $\mathrm{i}-\mathrm{ZnO}(300 \mathrm{~s})$.

cross-sectional view of the multilayer stacking in the case of a i$\mathrm{ZnO}(120 \mathrm{~s})$ cell. The cell performances have been evaluated by recording the current-voltage curves under calibrated 1 sun illumination. In Fig. 5b, we present the curves measured in the short-circuit (SC) to forward bias (FB) and in the FB to SC scanning directions to account for the $J-V$ curve hysteresis. ${ }^{38}$ The photovoltaic parameters of typical cells are tabulated in Table 2 for the two scan directions. The cells prepared with i$\mathrm{ZnO}(20 \mathrm{~s})$ had a very low efficiency with a low $V_{\mathrm{oc}}, \mathrm{FF}$ and $J_{\mathrm{sc}}$ because the oxide selective contact was almost absent in that case. It resulted in the direct contact of the perovskite with the

Table 2 Effect of the deposition time of the i-ZnO layer on the $\mathrm{J}-\mathrm{V}$ curve characteristics (AM1.5G filtered full 1 sun illumination, FF is the curve fill factor)

\begin{tabular}{lllllr}
\hline $\begin{array}{l}\text { i-ZnO deposition } \\
\text { time/s }\end{array}$ & $\begin{array}{l}\text { Scan } \\
\operatorname{direction}^{a}\end{array}$ & $V_{\text {oc }} / \mathrm{V}$ & $J_{\text {sc }} / \mathrm{mA} \mathrm{cm}^{-2}$ & $\mathrm{FF} / \%$ & PCE/\% \\
\hline \multirow{2}{*}{20} & SC-FB & 0.41 & 11.2 & 20.59 & 0.94 \\
\multirow{3}{*}{50} & FB-SC & 0.29 & 5.43 & 25.11 & 0.39 \\
& SC-FB & 0.89 & 20.1 & 37.2 & 6.68 \\
120 & FB-SC & 0.87 & 18.9 & 45.5 & 7.51 \\
& SC-FB & 0.89 & 23.1 & 50.0 & 10.25 \\
300 & FB-SC & 0.91 & 22.6 & 52.9 & 10.91 \\
& SC-FB & 0.81 & 21.8 & 54.07 & 9.56 \\
& FB-SC & 0.84 & 21.8 & 54.02 & 9.89
\end{tabular}

${ }^{a}$ SC-FB: short circuit to forward bias. FB-SC: forward bias to short circuit.
ITO substrate layer and the cell was not stable. The $\mathrm{i}-\mathrm{ZnO}(50 \mathrm{~s})$ cell exhibited a higher $J_{\mathrm{sc}}, V_{\mathrm{oc}}$ and FF. The best PCE was achieved for $\mathrm{i}-\mathrm{ZnO}(120 \mathrm{~s})$ devices. In that case the $J_{\mathrm{sc}}$ was high $(\sim 23$ $\mathrm{mA} \mathrm{cm}^{-2}$ ). Taking the actual cell PCE as the mean value for the two scan directions, ${ }^{38}$ we found an actual PCE value of $10.6 \%$. Increasing the $\mathrm{i}-\mathrm{ZnO}$ deposition time was detrimental for the cell performances. In that case the FF slightly increased, but the cell $V_{\mathrm{oc}}$ and $J_{\mathrm{sc}}$ were reduced compared to $\mathrm{i}-\mathrm{ZnO}(120 \mathrm{~s})$. The slight photocurrent reduction of $\mathrm{i}-\mathrm{ZnO}(300 \mathrm{~s})$ cannot be assigned to a reduced light harvesting efficiency since the active layer absorbance does not vary significantly with the i-ZnO deposition time (Fig. 4c). The IPCE curves (Fig. S4, ESI†) suggest that the charge injection/collection is slightly reduced in i$\mathrm{ZnO}(300 \mathrm{~s})$ giving rise to a slightly lower $J_{\mathrm{sc}}$.

In order to understand the variation in the $V_{\mathrm{oc}}$ and $\mathrm{FF}$ between the most efficient devices, impedance spectroscopy (IS) measurements have been performed under illumination over a large applied voltage and frequency range. We have focused on

(a)

(b)

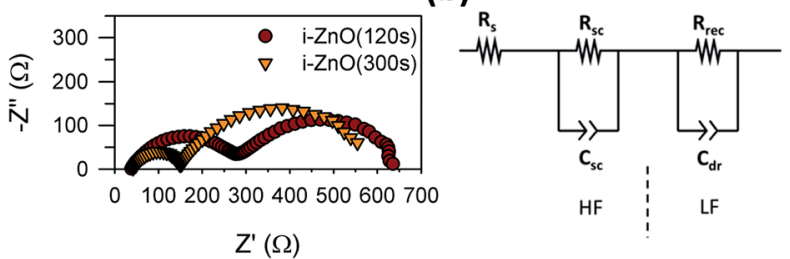

(c)

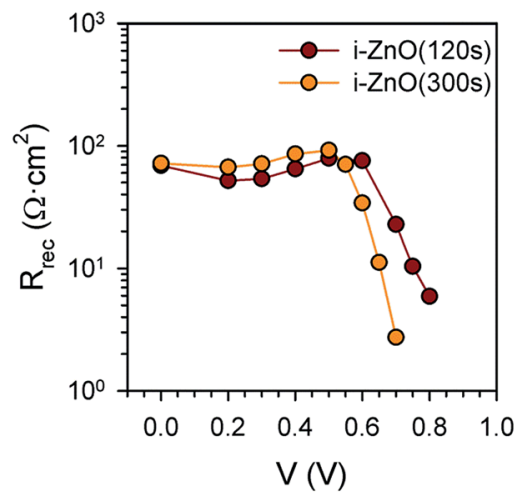

(d)

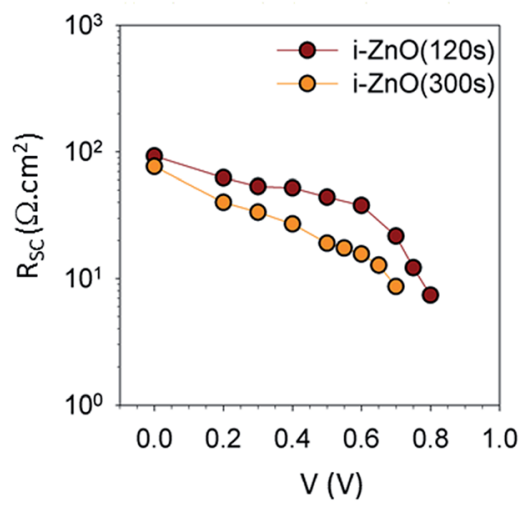

Fig. 6 (a) Nyquist plot under illumination at $0.5 \mathrm{~V}$ applied bias. (b) Equivalent circuit employed for fitting the impedance spectra (HF: high frequency; LF: low frequency). (c) Recombination resistance, $R_{\text {rec }}$, and (d) selective contact resistance, $R_{\mathrm{sC}}$, under illumination at different applied biases, $V$. 
stable cells, $\mathrm{i}-\mathrm{ZnO}(120 \mathrm{~s})$ and $\mathrm{i}-\mathrm{ZnO}(300 \mathrm{~s})$, where the $\mathrm{ZnO}$ covering of ITO is complete. Those with shorter i-ZnO layer deposition times were not stable under prolonged polarization at various voltages, as required for an adequate IS analysis. The obtained IS spectra only contain a couple of arcs (Fig. 6a). These spectra can be fitted using the simple equivalent electrical circuit shown in Fig. $6 \mathrm{~b} .{ }^{20} R_{\mathrm{s}}$ is the contact resistance due to wiring and ITO layer measured at high frequency. The high frequency arc is ascribed to the parallel association of $R_{\mathrm{sc}}$, a resistance dominated by the selective contact (sc) in parallel with $C_{\mathrm{sc}}$, which is an interfacial capacitance. $R_{\mathrm{sc}}$ resistance is influenced by transport resistance at the ETL and HTL, but also by the charge transfer resistance at the sc-perovskite interfaces. ${ }^{20}$ In most of the cases, the current between two different materials experiences a resistive effect when the charge moves from one material to the other, originating a charge transfer resistance at the interface. This interfacial resistance decreases as the interfacial area increases as resistivity is inversely proportional to the area. In the analyzed case, as perovskite/ HTL does not change, the observed differences can be attributed to the perovskite/ZnO interface. At low frequency, another arc is found, originating from the parallel association of $R_{\text {rec }}$, the recombination resistance, in parallel with a dielectric relaxation capacitance ${ }^{39}$ (modelled by a constant phase element (CPE)) and related to the perovskite layer.

Very similar $R_{\mathrm{s}}, C_{\mathrm{sc}}$ and $C_{\mathrm{dr}}$ have been obtained for both samples (see Fig. S5, ESI $\dagger$ ). However, significant information can be obtained from $R_{\mathrm{sc}}$ and $R_{\mathrm{rec}}$ analysis. Fig. 6c shows the $R_{\mathrm{rec}}$ for both cells. At low applied voltages similar values are obtained but at a high applied bias, i- $\mathrm{ZnO}(120 \mathrm{~s})$ presents the highest recombination resistance (the lowest recombination rate). Consequently, higher $V_{\text {oc }}$ observed for $\mathrm{i}-\mathrm{ZnO}(120 \mathrm{~s})$ in comparison with $\mathrm{i}-\mathrm{ZnO}(300 \mathrm{~s})$ can be unambiguously explained as a result of the lower recombination. ${ }^{40}$ Moreover, higher $R_{\mathrm{sc}}$ has been also obtained for the $\mathrm{i}-\mathrm{ZnO}(120 \mathrm{~s})$ sample (Fig. 6d). As the HTL material and its deposition process are analogous for both samples, the differences observed can be attributed to the differences introduced by the ETL. The influence of ETL in $R_{\mathrm{sc}}$ is associated with two factors, firstly, the transport resistance of electrons through the ZnO ETL. Due to the rather good conductivity of $\mathrm{ZnO}$ layers, this resistance can be considered low even for a thicker $\mathrm{ZnO}$ layer (sample i-ZnO(300 s)). Secondly, we can suppose that $R_{\mathrm{sc}}$ is mainly governed by the charge transfer resistance at the $\mathrm{ZnO}$-perovskite interface, decreasing as the roughness of the interface increases. This fact can explain the slightly lower FF of this sample in comparison with that of the $\mathrm{i}-\mathrm{ZnO}(300 \mathrm{~s})$ sample, as this resistance contributes to the total series resistance (Table 2).

The described i-ZnO deposition technique is performed under soft conditions and low temperature. Therefore, it is compatible with lightweight plastic substrates. We have successfully deposited this ETL on PET/ITO sheets and we have prepared flexible solar cells as shown in Fig. S6 (ESI $\dagger$ ). The efficiency is low compared to those on ITO/glass (Fig. S6†) and would need optimization, however, the prepared cells clearly establish the proof of concept that electrodeposition is a relevant technique for the preparation of ETM for flexible PSCs.

\section{Conclusions}

We have reported here the development of a simple and fast deposition method of ETL at low temperature. The progressive nucleation and growth yield to a fully covering film after only two minutes of deposition time. XRD, photoluminescence and Raman spectroscopy analyses have shown that the covering layers are made of high quality ZnO. Moreover the technique can be implemented on ITO-coated flexible plastic substrates. An optimized deposition time of 2 minutes has been defined for their application as ETL in perovskite solar cells. For a longer deposition time, the efficiency decreases due to a slight reduction in $J_{\mathrm{sc}}$ and $V_{\mathrm{oc}}$. Impedance spectroscopy investigation has shown that the charge transfer resistance between perovskite and ZnO ETL depends strongly on the roughness of the $\mathrm{ZnO}$ layer, decreasing as this parameter increases. On the other hand the $\mathrm{ZnO}$ ETL also influences the recombination rate. The optimum conditions with an adequate balance of these factors have been determined for PSCs with close to $11 \%$ efficiency, prepared completely under low temperature conditions. The present work could have important implications in the implementation of low cost industrial processes.

\section{Acknowledgements}

J.Z. acknowledges the Guangzhou Government for scholarship (Oversea Study Program of the Guangzhou Elite Project). We thank Dr Odile Majerus for the help in Raman spectroscopy measurements.

\section{Notes and references}

1 M. Grätzel, R. A. Janssen, D. B. Mitzi and E. H. Sargent, Nature, 2012, 488, 304.

2 R. Plass, S. Pelet, J. Krueger, M. Grätzel and U. Bach, J. Phys. Chem. B, 2002, 106, 7578.

3 C. Goh, S. R. Scully and M. D. McGehee, J. Appl. Phys., 2007, 101, 114503.

4 H. S. Kim, C. R. Lee, J. H. Im, K. H. Lee, T. Moehl, A. Marchioro, S. J. Moon, R. Humphry-Baker, J. E. Moser and M. Grätzel, Sci. Rep., 2012, 2, 591.

5 M. M. Lee, J. Teuscher, T. Miyasaka, T. N. Murakami and H. J. Snaith, Science, 2012, 338, 643.

6 J. Burschka, N. Pellet, S. J. Moon, R. Humphy-Baker, P. Gao, M. K. Nazeeruddin and M. Grätzel, Nature, 2013, 499, 316.

7 M. Liu, M. B. Johnson and H. J. Snaith, Nature, 2013, 501, 395.

8 J. H. Heo, S. H. Im, J. H. Noh, T. N. Mandal, C. S. Lim, J. A. Chang, Y. H. Lee, H. J. Kim, A. Sarkar, M. K. Nazeeruddin, M. Grätzel and S. I. Seok, Nat. Photonics, 2013, 7, 487.

9 J. H. Noh, S. H. Im, J. H. Heo, T. N. Mandal and S. I. Seok, Nano Lett., 2013, 13, 1764.

10 N. J. Jeon, J. H. Noh, Y. C. Kim, W. S. Yang, S. Ryu and S. I. Seok, Nat. Mater., 2014, 13, 897.

11 H. Zhou, Q. Chen, G. Li, S. Luo, T. B. Song, H. S. Duan, Z. Hong, J. You, Y. Liu and Y. Yang, Science, 2014, 345, 542. 
12 F. Hao, C. C. Stoumpos, D. H. Cao, R. P. H. Chang and M. G. Kanatzidis, Nat. Photonics, 2014, 8, 489.

13 M. Grätzel, Nat. Mater., 2014, 13, 838.

14 Research Cell Efficiency Records, NREL, http:// www.nrel.gov/ncpv/images/efficiency_chart.jpg.

15 T. Pauporté, E. Jouanno, F. Pellé, B. Viana and P. Aschehoug, J. Phys. Chem. C, 2009, 113, 10422.

16 B. Liu and H. C. Zeng, J. Am. Chem. Soc., 2003, 125, 4430.

17 J. Zhang, P. Barboux and T. Pauporté, Adv. Energy Mater., 2014, 4, 1400932.

18 D. Q. Bi, G. Boschloo, S. Schwarzmuller, L. Yang, E. M. J. Johansson and A. Hagfeldt, Nanoscale, 2013, 5, 11686.

19 M. H. Kumar, N. Yantara, S. Dharani, M. Grätzel, S. Mhaisalkar, P. P. Boix and N. Mathews, Chem. Commun., 2013, 49, 11089.

20 E. J. Juarez-Perez, M. Wussler, F. Fabregat-Santiago, K. Lakus-Wollny, E. Mankel, T. Mayer and W. Jaegermann, J. Phys. Chem. Lett., 2014, 5, 680.

21 D. Liu and T. L. Kelly, Nat. Photonics, 2014, 8, 133.

22 K. Mahmood, B. S. Swain and H. S. Jung, Nanoscale, 2014, 6, 9127.

23 D. Y. Son, J. H. Im, H. S. Kim and N. G. Park, J. Phys. Chem. C, 2014, 118, 16567.

24 J. Dong, Y. Zhao, J. Shi, H. Wei, J. Xiao, X. Xu, J. Luo, J. Xu, Y. Li, Y. Luo and Q. Meng, Chem. Commun., 2014, 50, 13381.

25 C. Magne, T. Moehl, M. Urien, M. Grätzel and T. Pauporté, J. Mater. Chem. A, 2013, 1, 2079.

26 M. Law, L. E. Greene, J. C. Johnson, R. Saykally and P. D. Yang, Nat. Mater., 2005, 4, 455.
27 V. M. Guérin and T. Pauporté, Energy Environ. Sci., 2011, 4, 2971-2979.

28 M. Izaki and T. Omi, Appl. Phys. Lett., 1996, 68, 2439.

29 M. Izaki and T. Omi, J. Electrochem. Soc., 1996, 143, L53.

30 T. Shinagawa, M. Chigane, K. Murase and M. Izaki, J. Phys. Chem. C, 2012, 116, 15925.

31 M. Izaki, T. Ohta, M. Kondo, T. Takahashi, M. Fariza, J. Sasano, T. Shinagawa and T. Pauporté, ACS Appl. Mater. Interfaces, 2014, 6, 13461.

32 L. Etgar, O. Gao, Z. Xue, Q. Pen, A. K. Chandiran, B. Liu, M. K. Nazeeruddin and M. Grätzel, J. Am. Chem. Soc., 2012, 134, 17396.

33 T. Pauporté and I. Jirka, Electrochim. Acta, 2009, 54, 7558.

34 Powder Diffraction File Card 36-1451, Joint Committee on Powder Diffraction Standards, ICDD, Newtown Square (PA), 2001.

35 O. Lupan, T. Pauporté, L. Chow, B. Viana, F. Pellé, B. Roldan Cuenya, L. K. Ono and H. Heinrich, Appl. Surf. Sci., 2010, 256, 1895.

36 R. Cusco, E. Alarcon-Llado, J. Ibanez and L. Artus, Phys. Rev. B: Condens. Matter Mater. Phys., 2007, 75, 165202.

37 O. Lupan, L. Chow, L. K. Ono, B. Roldan Cuenya, G. Chai, H. Khallaf, S. Park and A. Schulte, J. Phys. Chem. C, 2010, 114, 12401.

38 H. J. Snaith, A. Abate, J. Ball, G. E. Eperon, T. Leijtens, N. K. Noel, S. D. Stranks, T. J. W. Wang, K. Wojciechowski and W. Zhang, J. Phys. Chem. Lett., 2014, 5, 1511.

39 J. Bisquert, L. Bertoluzzi, I. Mora-Sero and G. GarciaBelmonte, J. Phys. Chem. C, 2014, 118, 18983.

40 B. Suarez, V. Gonzalez-Pedro, T. S. Ripolles, R. S. Sanchez, L. Otero and I. Mora-Sero, J. Phys. Chem. Lett., 2014, 5, 1628. 